\title{
Not Because My Heart is Gone; Simply The Other Side: Francesca Woodman's Relational and Ephemeral Subjectivity at the Limit of The Image
}

\author{
Anna Backman Rogers \\ University of Gothenberg \\ anna.backman.rogers@gu.se
}

Originally published in Female Agency and Documentary Strategies: Subjectivities, Identity and Activism (2017) edited by Boel Ulfsdotter and Anna Backman Rogers and reprinted here by permission from Edinburgh University Press. Accepted 16 August 2021; published 5 September 2021.

\begin{abstract}
Francesca Woodman's personal history, more specifically her suicide at the age of only twenty-two years old, is often used as an heuristic framework through which her highly intricate and complex photographic work is read retroactively. This essay argues that such readings fundamentally miss Woodman's fascination with liminality and states of transition precisely in order to contain her fundamentally ambiguous images within a generic narrative that serves to cast her in the role of a tragic, female artist. Backman Rogers wholly rejects this sexist conflation of the artist's biography with her art.
\end{abstract}

Keywords: Francesca Woodman; liminality; photography; gender; feminism; feminist art

It is that life as lived by me now is a series of exceptions ... I was (am?) not unique but special. This is why I was an artist ... I was inventing a language for people to see the everyday things that I also see ... nothing to do with not being able to "take it" in the big city, or with self-doubt or because my heart is gone ... and not to teach people a lesson. Simply the other side. [Francesca Woodman's last diary entry; Steinhauer, 2012]

The opacity of the subject may be a consequence of its being conceived as a relational being, one whose early and primary relations are not always available to conscious knowledge. Moments of unknowingness about oneself tend to emerge in the context of relations to others, suggesting that these relations call upon primary forms of relationality that are not always available to explicit and reflective thematization. If we are formed in the context of relations that become partially irrecoverable to us, then that opacity seems built into our formation and follows from our status as beings who are formed in relations of dependency. [Butler, 2005, p. 20] 


\section{Introduction}

Francesca Woodman's personal history, more specifically her suicide at the age of only twenty-two years old, is often used as an heuristic framework through which her highly intricate and complex photographic work is read retroactively. Peggy Phelan (2002), for instance, in an essay that despite beautiful elucidation of her work elides Woodman's fascination with photography as the commemorative medium of the twentieth century (a century that paid witness to death and genocide on an astronomic scale) and the tragic facts of her own biography, has asserted that Woodman's work is a kind of ritualized rehearsal for an act of disappearance ${ }^{1}$; Isabella Pedicini has noted further that there is a marked tendency amongst scholars and critics to equate her photographs with a suicidal psyche. Indeed, Pedicini remarks that such readings eschew Woodman's fascination with liminality and states of transition precisely in order to contain her fundamentally ambiguous images within a generic narrative that serves to cast her in the role of a tragic, female artist; she writes that her work is read: "not in relation to her own investigation of an identity poised inevitably between life and death, but out of a determination to find endless tropes within her work of anguish, restlessness, and female depression" (2012, p. 37). Moreover, accounts of Woodman that portray her as an intense, passionate and prodigiously talented young artist loom large over, and at times obscure, the considerable archive of images she left behind her-some eight hundred photographs, many of which are self-portraits. While the facts of Woodman's biography may enrich our reading of her work, they are certainly not imperative for drawing out the multifaceted and fundamentally philosophical nature of her images. I contend, alongside scholars such as Chris Townsend (2007) and Pedicini (2012), that Woodman's persistent self-documentation evinces a will that radically fights against erasure. Her images are not biographical, but the presence of the artist is always insistently and subversively there. Yet what her fleshy manifestation within these images reveals is the limitation, if not the impossibility, of capturing subjectivity as presence; as such, Woodman's work, I argue, dramatizes and complicates the moment in which we come into being for someone or something else - a process which is always beset by ideology. Woodman's images precipitate the question of what is at stake when one is both the subject and object of the gaze, and whether the stakes are raised when the central focus of the image is the female body.

Woodman's performance of selfhood - for Woodman is, above all else, a performative artistrenders clear the vulnerability, mutability and ephemerality of subjectivity. Woodman's selfportraits trouble and question the notion of persistent and exhaustive identity — and by extension the possibility of self-authorship - since they capture the moment in which an ability to "give an account of oneself" (Butler, 2005) radically fails. I would suggest, then, that Woodman's work is far more complex than any biographical reading of her work can allow for

\footnotetext{
${ }^{1}$ Phelan suggests that we should acknowledge "the possibility that suicide might be the result of a well-considered logic and that Woodman's photography was a way to help her, and us, survive her disappearance from the surface of the visible world... And perhaps it was impossible to propose in 1986, when Woodman's suicide was still recent and her work was largely unknown. But now, with some of the benefits of afterwardness, we can return more directly to the insights Woodman offered us about art and death" (Phelan, 2002, p. 991) and that "Woodman invites us to see her suicide, like her art, as a gift. Perhaps not the one we might have wished for, but the one she gave us when she did not have anything to give" (Phelan, 2002, p. 1002). In short, she posits, not un-controversially, Woodman's suicide as an inextricable part of her artistic achievement.
} 
precisely because her photographs insistently question central tenets that form the basis of what it means to provide a personal and descriptive account of oneself. To read her work as the externalisation of psychic pain or as a self-destructive iteration is to miss the fact that her work centres on the very mechanics of photography as the medium that brings absence and presence into disquieting proximity. As Amy Sherlock notes: "ultimately, this is what Woodman's self-portraits so powerfully articulate: the fleetingness of presence always touching the limit of absence. Woodman is never there where she is" (Sherlock, 2013, p. 388). In other words, her work professes an awareness of what will always remain radically out of reach however much she may try to grasp it artistically; what is made manifest in a number of Woodman's pictures is something akin to Barthes' notion of the punctum (2000, pp. 40-49), that unintended, ambiguous, and fundamentally unreadable aspect of the image which conjures up, by making the past forcefully present, an ineffable sense of not only what is already lost to the past, but also a queasy and disquieting sense of one's own mortality. That one cannot lay claim to or explain this sense of what is already lost in the photograph only compounds its fundamentally odd and decentring nature: as Barthes writes: "( $\mathrm{t}$ )he incapacity to name is a good symptom of disturbance" (2000, p. 51). Woodman, in a sense, presents herself as always already missing since her identity never coincides with her photographic likeness and that likeness, in turn, is presented in such a way to obfuscate and complicate any notion of a consistent and abiding sense of self.

This is not a tragic impulse (a misreading which the details of her own biography have been deployed to promulgate), but rather a concerted and intelligent engagement with what it might mean to be captured and frozen precisely as an image at the moment in which one comes into being for an other-whether that other is an observer or the apparatus. Woodman's work is undoubtedly concerned with the elision of photography with commemoration, mortality and mourning, but it would be erroneous to conclude that this is based in self-destructive tendencies rather than a keen fascination with the tension between stillness and movement, mortality and immortality implicit within the photographic form itself and what happens when one abandons oneself to the photographic apparatus: that is, the violence of stasis that is wrought on the body as a result. What Woodman gestures towards in her work are the in-between, obscure and ambiguous moments that elude and refuse capture and exhaustive understanding. It is not her own death, then, with which she is fascinated, but on the contrary the small dose of death that the moment of photographic capture delivers on the human form; as Susan Sontag has noted astutely: "all photographs are memento mori. To take a photograph is to participate in another person's [...] mortality, vulnerability, mutability. Precisely by slicing out this moment and freezing it, all photographs testify to time's relentless melt" (Sontag, 1979, p. 15). It is this essential vulnerability that is felt in the face of exposure to a world outside of oneself that Woodman's work so sensitively dramatizes. In short, however much one may try to control the making of one's own image, there will nearly always be an infinitesimal detail that precludes the possibility of sovereignty over oneself and one's representation-life always essentially escapes capture.

It is not my intention here to discredit autobiographical readings of Woodman's work, but rather to set aside the facts of her biography in order to examine the manifold ways in which her work throws into crisis the ontological stability of the image through a determined engagement with space, time, and reflexivity. As such, the Francesca Woodman I am writing of is an 
embodied, fleshy, and inquisitive artist who is more invested in presenting her corporeal interaction with the world and other people than she is in externalising her inner world and sense of self-which, by necessity, remains highly elusive. Woodman may have focused her camera on her own body, but the images she produced are revelatory of a kind of phenomenological and feminine being-in-the-world in which the human body is rendered deeply imbricate with its environment — an environment that always precedes and exceeds it; as Pedicini argues: "Woodman's work celebrates the contiguity of all types of matter and establishes a connection between the body of the artist and the objects with which she becomes entangled to the point of complete synthesis" (2012, p. 98). For what she asks us to do insistently is to look again, to look askance, at this world that we inhabit communally with and through our bodies. Woodman's work is far from being narcissistic, then, since it expands outwards in order to posit the very condition for the possibility of existence as relationality to other people and to the world. As such, what Woodman dramatizes in her images is the excessive nature of existence and the impossibility of its summation or capture in isolation because human existence is always contaminated by its inter-relationality. Additionally, her work reframes or recasts this process of trying to capture as a form of death: a death which Woodman herself eludes by making herself persist and endure as movement within the confinement of an image that, by its very nature, extrapolates and freezes life.

\section{Untitled: Subjectivity at The Limits of The Photographic Frame}

It is perhaps somewhat pedestrian to note that we live in an image-saturated culture in which, according to Google statistics, over ninety three million self-portraits are uploaded daily to social media platforms such as Facebook, Twitter and Instagram (Mirzoeff, 2015, p. 65), but as an overwhelmingly popular - and therefore important - current iteration in the history of self-portraiture it provides a fecund reference point, by way of contrast, with Woodman's work. This wave of socially sanctioned narcissism invokes tendencies amongst people - the overwhelming majority of whom are female young adults and teenagers - to dissect, choreograph, distort, re-frame, package, airbrush and filter their own image in order to shore up a virtual, online identity; moreover the prevailing norms of beauty that govern this form of imagemaking ensure that these images recuperate and appropriate visual tropes that play to the male gaze. Indeed, Samsung has recently launched a model of mobile telephone camera that claims to enhance the human face by automatically slimming it down, enlarging the eyes and mouth and removing natural blemishes and pores via a free application known as "Beauty Face"; perhaps it will be of interest to readers to note that the primary demographic this "app" is aimed at is the young female market and, more disturbingly, that the image being propagated and sold as beautiful is one that resembles the face of a small doll (an aesthetic which the pornographic industry draws upon readily). The implication of this automatic amelioration of appearance is that one should always unhesitatingly comply with the impossible and therefore arguably pernicious norms of the beauty industry ${ }^{2}$.

\footnotetext{
${ }^{2}$ See http://www.samsung.com/uk/consumer/flagship/SM-C1010ZWABTU/tutorial/tutorial/beauty_face_correct_facial.html (accessed 9/5/2016).
} 
As such, the "selfie" is, at its very worst, a malign tool for prompting young women to hail their position as normative female subjects by making them complicit with an oppressive form of patriarchal, regressive politics ${ }^{3}$. What is at stake in this painstaking and laborious process is not merely approbation by one's peer group - although this has surely intensified within such a hermetic and false environment - but one's very sense of self. For what this perpetual cycle of obsessive and compulsive behaviour reveals is that if one is not constantly seen, one ceases to exist altogether. As Guy Debord (1992) and Jean Baudrillard (1994) already predicted with the rise of spectacular and digital cultures, the virtual image has now lost its representative function and has come to stand in for the actuality of the person. This perverse reversal demands, therefore, that a person's validity depends on her ability to approximate her own virtual and highly artificial image - a dilemma which feminist scholars from Naomi Wolf (1991) to Angela McRobbie (2015) have noted affects women acutely. Young women, especially, seem unwittingly able to acquiesce to a form of mediation that ensures internalisation of the deleterious norms of the ideology that governs this process of mediation in the first place. It is my contention that female virtual identity - as it is currently manifest - is characterised by an obsession with one's own image as it may be seen by an (implicitly male) observer; indeed, sociologist Ben Agger has claimed that: "the selfie is the male gaze gone viral" (Mirzoeff, 2015, p. 64). The forms of identity it creates are repetitive (by which I mean the ubiquity of certain gestures, repeated framings, and hash-tags), homogenous and static. The selfie functions as a clichéd image precisely by evacuating the human subject of her complexity and irreducibility in favour of singularity and superficiality. However disposable and spurious it may be, it fixes and reduces identity so that alterity-oddness, if you will— is eradicated.

I am not invoking or offsetting this comparison between Woodman's work and the contemporary culture of the selfie to be facetious, but rather to elaborate in what follows on what sets Woodman's concerns and artistry apart from more flagrantly narcissistic and unthinking forms of image-making and meaning. Indeed, Woodman's penetrating self-examination works to evacuate rather than affirm her sense of identity and to challenge and complicate her relationship with her observer; as Pedicini argues: "Woodman was not motivated by narcissism [...]. She manifests her self in a body which screams and dissimulates, forever blurring and disappearing in the space of the photographic narrative" $(2012$, p. 22). If the selfie is a catalyst to bring into being a form of, albeit shallow, false and superficial, identity, Woodman's selfportraiture throws into crisis any notion of a persistent and abiding self that can be captured or framed. Woodman, as a photographic subject, is determinedly and defiantly evasive. I would suggest that it is Woodman's preoccupation with time and movement and her engagement with the photographic apparatus as an already ideologically loaded medium, especially when turned on her own naked likeness, that precisely gestures towards the impossibility of laying claim to any definitive subjectivity. Woodman's images visually translate the existential problem of I is another by presenting the photographic body precisely as a liminal body in movement that is always on the cusp of becoming other; her work continually foregrounds processes of change and metamorphosis. This is particularly evident in a series such as Space (see figure

\footnotetext{
${ }^{3}$ Rosalind Gill has written on this disturbing phenomenon at length across a series of articles. See in particular Elias \& Gill (2017).
} 
1) in which the human form is refracted and dispersed through space via the use of a slow shutter release. What we see here is evidently not a statement of identity on the part of the artist, but rather a representation of her body under the conditions of time, space, light and movement. The focal point of this image is movement in and of itself. If one were to extend this movement out as visual metaphor, this image functions as a translation of the processes of metamorphosis and change that are intrinsic to any object and being that exists in duration. As such, what we have is a statement on the impossibility of rendering being as change as a static entity - this image is both, very deliberately so, an attempt and a failure to essay capture of the human body. This is the radical point of failure, which I wrote of earlier, which is incorporated into the very form of her images and constitutes the ambiguous and tentative "meaning" at the heart of her work. It is this determination to get at the "truth" of the image, a truth which lies in the contradiction implicit in repeatedly failed attempts to assert here I am, that marks her work out as deeply existential. Her On Being An Angel (1977) and Angel (1977) series, recast the human body as a liminal entity within a profane environment (perhaps symbolised by the detachment of her wings from her body). Here, the body is suspended in movement and duration as an entity that comes into being through a momentary, fleeting and fragile (im)possibility: the defiance of gravity. The point of capture - the height of Woodman's ascension-delineates visually the moment in which she both rises and begins to fall. The indistinct, blurred contortions of her body register a state of ambiguity and resolute in-betweenness that can be said to be characteristic of much of her work.

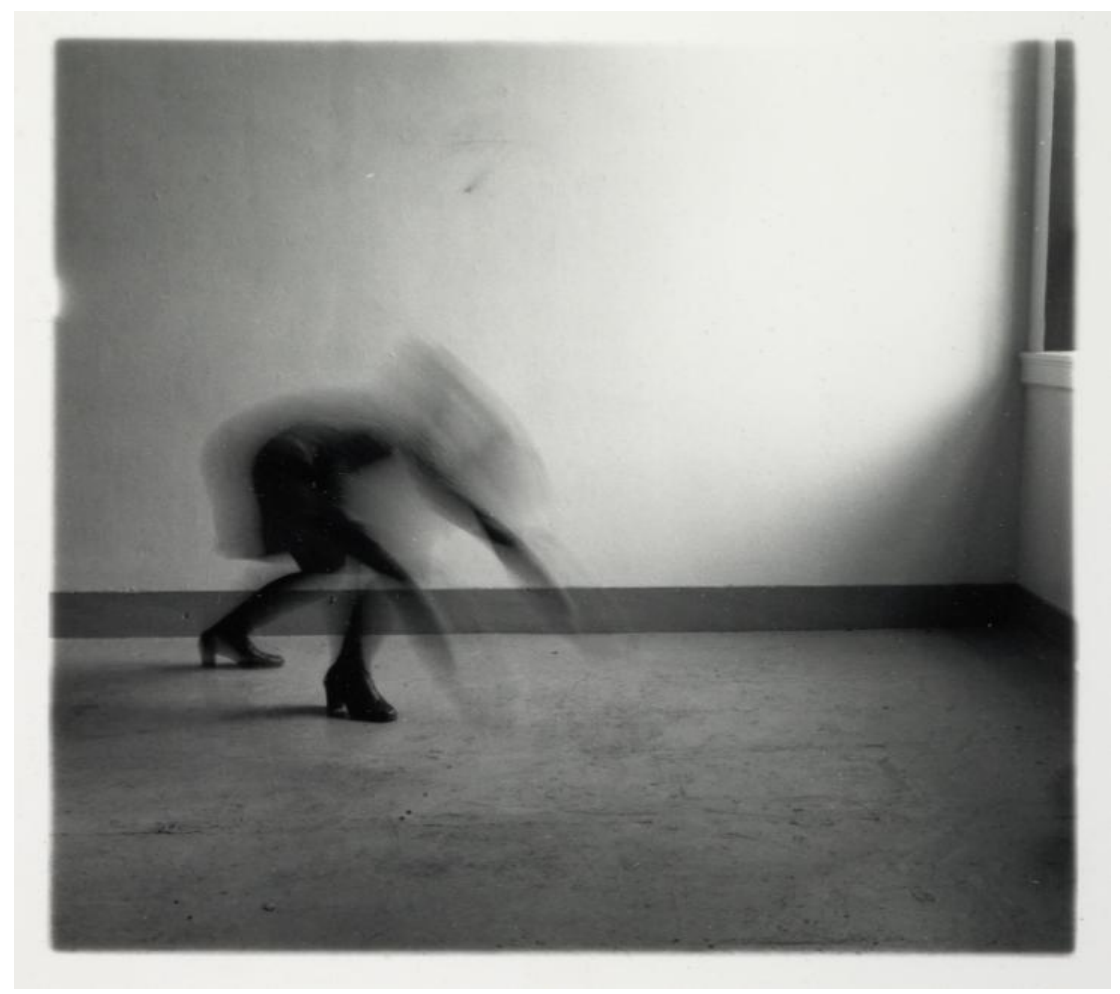

Figure 1: Space, Providence, Rhode Island, 1975-1978 
Judith Butler, in her work on subjectivity, community and ethics ${ }^{4}$, identifies this tension in any attempt to gain purchase on or lay claim to a coherent, self-same identity; she writes:

if the identity we say we are cannot possibly capture us and marks immediately an excess and opacity that falls outside the categories of identity, then any effort "to give an account of oneself" will have to fail in order to approach being true. (2005, p. 42)

Moreover, she suggests that in questioning the manifold ways in which meaning is madethat is, the processes by which someone or something comes to be recognised as part of a cultural narrative that precedes its being - and the forms of mediation that make an object collectively apprehensible as something, we are also examining the terms under which our own subjectivity becomes meaningful and personhood is produced; she writes: "to call into question a regime of truth, where that regime of truth governs subjectivation, is to call into question the truth of myself and, indeed, to question my ability to tell the truth about myself, to give an account of myself" (Butler, 2005, p. 23). It is my contention that Woodman sets herself the artistic task of questioning how one comes to be seen and what this tells us about the nature of human identity at the centre of her work.

By interrogating identity, her work undercuts the possibility of authorship by foregrounding the ways in which we are never fully in control of ourselves because that self is inextricably caught up in processes that already shape and delimit our subjectivity. Her work also reveals the extent to which our sense of self is dependent on and constituted incontrovertibly by and for another and that this relationship contains an implicit violence in its reduction of our complexity. What Woodman's work both stages and fights against is this dynamic in which we wrestle with our identity through the gaze of another. However suffocating this relation is, it is also fundamental to our very existence as a human subject because we often make sense of our lives through collective cultural narratives (of which the self-portrait is but one example) and while it is possible (and right) to contest the boundaries of those narratives, trying to lead a life outside of narrative altogether results in obscurity as a form of death-nobody can survive a radically non-narratable life (Butler, 2005, p. 60). As Butler notes:

I am not, as it were, an interior subject, closed upon myself, solipsistic, posing questions of myself alone. I exist in an important sense for you, and by virtue of you. If I have lost the conditions of address, if I have no "you" to address, then I have lost "myself" [...] one can tell an autobiography only to another $[\ldots]$ without the "you", my own story becomes impossible. (2005, p. 32)

Woodman's work does not reveal a consistent and abiding self, but rather the ways in which the photographic apparatus works to evacuate that self whilst foregrounding the photographic apparatus itself. Woodman is supremely aware that in exposing herself for the camera, she is also performing for another. In their refusal of stasis and fixity, her photographs are attuned to the precarity and fundamental unpredictability of the moment in which they are made - a moment that is contextualised and subsists within duration. The self, as presented here, is vitally decentered and destabilized. As Harriet Riches notes:

\footnotetext{
${ }^{4}$ Although Butler is writing of autobiographical narratives and the ethical implications or (im)possibility of being able to claim sovereignty over one's own actions, I read the self-portrait as a form of self-narration, implicit within which is the possibility of being able to say "I": to be both the subject and object of one's own narrative.
} 
within a body of work in which her own body is a recurring subject, Woodman returned again and again to the ways in which her camera worked to displace any 'essence' of identity. Manipulating light to achieve effects of blurring and deep fragmentation and taking advantage of the camera's ability to crop and frame the body, Woodman exploits a photographic language of violence, as she explores the medium's proclivity for excising subjectivity from the world. (Riches, 2004, p. 99)

Implicit within Woodman's work is the fact that she knows her attempts to create her own image, to author her own identity, are shot through with impossibility and failure. Her agency is always compromised by her imbrication with the other, for whom she performs. As Amy Sherlock argues: "even in the case of the self-portrait one exposes oneself to the camera for another, to appear to another or [...] to see oneself from the side of the other" (2013, p. 380) and this duality in the image not only makes visible the violence implicit in the gaze (that I present myself as an image to be dissected and consumed), but also renders prevalent how Woodman is concerned with presenting and understanding herself as a seeing subject. Woodman places herself outside in order to gaze at her own image: as such, she sees herself as that "other" for whom she presupposes and creates her likeness. Yet if Woodman somehow manages to "capture" or hold herself as image as seen by another, her work also clarifies that this is by nature ephemeral and fleeting since one's self is always, as Chris Townsend argues, "outside one's own representation" (2007, p. 57). Woodman's project is one of excess in terms of the multiple ways in which her own subjectivity exceeds all interpretive, textual and ideological boundaries: she is defiant in her refusal to accede to any attempt at capture, even her own.

\section{A Woman is a Mirror for A Man: Confronting the Male Gaze}

Implied within Woodman's reflexive approach to making her self-image is a meditation on what it means to photograph the naked female form. She confronts phallocentricity via overt reference to violence (often wrought on the female body) and by exploring the implicit power dynamics of the gaze (that is coded as male). Woodman responds directly to the camera as an apparatus of ideology. As Claire Raymond notes: "legible in Woodman's self-portraits [...] is the traumatic violence of being made into an image, violence that Woodman's self-portraits [...] signify as implicitly linked to her body's femaleness" (2010, p. 32). Woodman is, in other words, both outside of and inside her own gaze - a discrepancy which opens up her imagemaking to possibilities of divergence and subversion. This duality, which can be harnessed and channelled as a form of politics, is a dynamic that John Berger has identified as intrinsic to and deeply rooted within female experience; he writes:

she comes to consider the surveyor and the surveyed within her as the two constituent yet always distinct elements of her identity as a woman [...]. Her own sense of being in herself is supplanted by a sense of being appreciated as herself by another [...] one might simplify this by saying: men act and women appear. Men look at women. Women watch themselves being looked at. This determines not only most relations between men and women but also the relation of women to themselves. The surveyor of woman in herself is male: the surveyed female. Thus she turns herself into an object—and most particularly an object of vision: a sight. (2008, p. 46) 


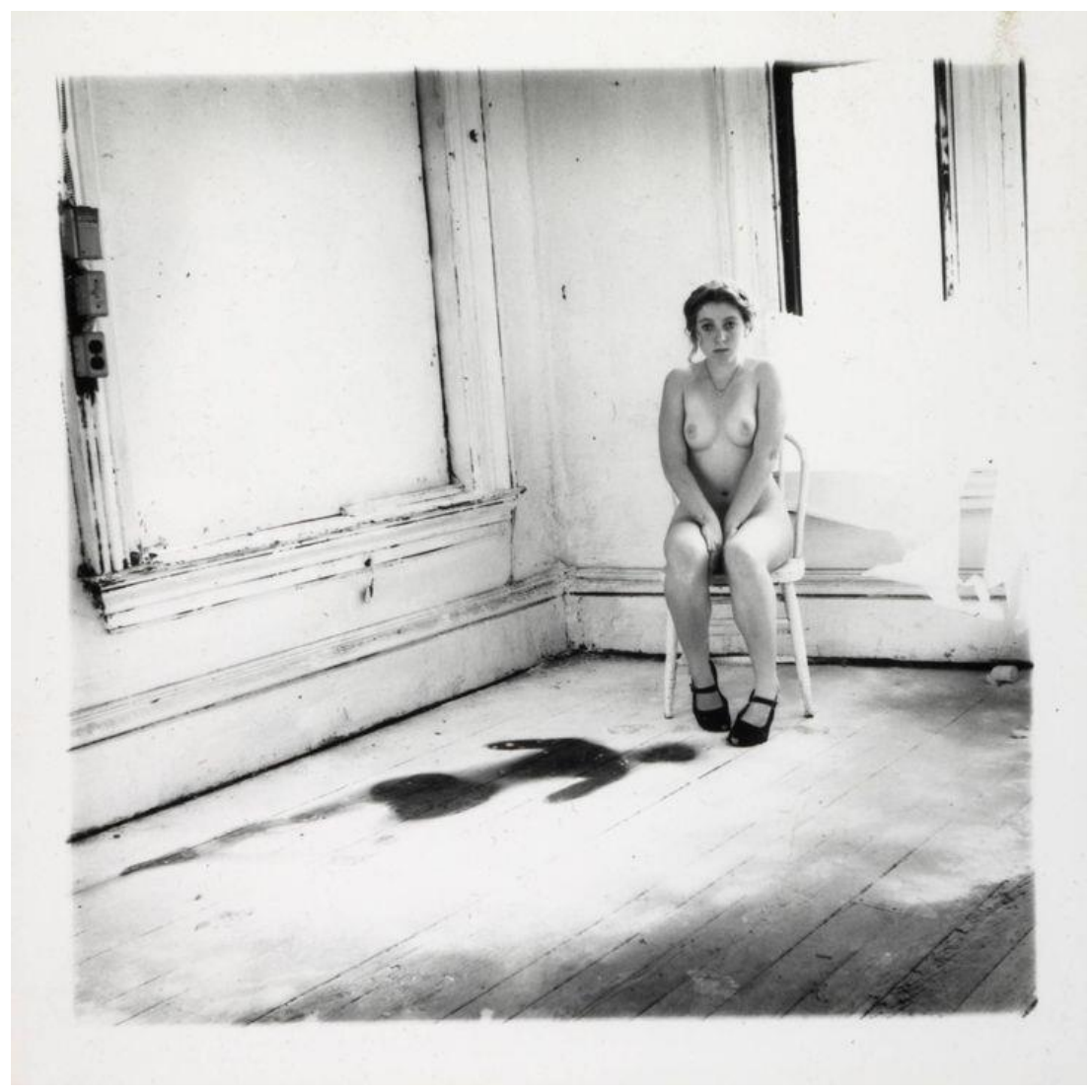

Figure 2: Untitled, Providence, Rhode Island, 1976

It is precisely the political implications of the gaze, which Berger appropriately identifies, and the subversive sites of contestation that are opened up within the disjuncture of being inside and outside of that gaze with which Woodman is concerned; and as Elisabeth Bronfen notes: "(a)ny female artist must engage with this double gaze of herself, always aware of the effect she has for the implied viewer" (2014, p. 19). Indeed, images, such as Untitled from 1976 (see figure 2), seem to allude to this directly via a complex order of the gaze: the gaze of the photographer/artist (who is not consistent with Woodman as she appears within the photographic frame), that of the anonymous and mechanical eye of the photographic apparatus, and that of Woodman herself as she sits aside her own form from within the confinement of the image. She is both active and passive in this image since it bifurcates her body into an adumbration of her own naked form, whilst offering her body precisely as "nude, seated female" to an anonymous observer (whose own gaze is filtered and directed through Woodman's choreography of this scene). It is Woodman's intense physical presence in the photograph and her gaze as an artist that compounds and complicates this image. Moreover, the deliberate placement of her arms serves to section off and draw attention, through partial concealment, to her nakedness and those parts of her body that tie her to essential (and therefore highly problematic) 
forms of identity politics that fuse "femaleness" with "femininity." However controlled this image of her likeness is though, it also elicits a palpable sense of her own vulnerability as a body that is there to be looked at and the simplicity with which her "shadow" is rendered speaks to the highly reductive and superficial nature of how the female body is often read within images (that she is reduced to her anatomical parts or to her body). Here, the collision of two presences within the frame - that of the fleshy embodied artist and the dark silhouette or outline of that body as it is inscribed on the floor's surface-disrupts and ruptures the surface of the image to reveal depth. Once again, Woodman signals towards the complexity of human subjectivity and the violence implicit in its reduction to a cliché (the French etymology of which precisely designates a photograph). As such, this image is as much a comment on Woodman's own process of self-documentation as it is an implicit indictment of patriarchal forms of visual culture at large that render the female body purely as a specious form of spectacle.

In I Could No Longer Play, I Could Not Play By Instinct (see figure 3), Woodman explicitly poses for the camera and her placement within the frame is rigorously choreographed and purposeful; by exposing and presenting herself as a body, once again, that is placed there to be gazed upon she integrates herself within an artistic tradition that is already codified within Western aesthetics. In this photograph, which draws explicitly on a Surrealist and somewhat misogynist visual history, Woodman displays to the viewer her seemingly mutilated and naked breast from which the photographic negative of her own image "bleeds." This is an image which makes manifest the inherent violence of objectification: that is, one is transformed into an object by and for an other; yet if Woodman places herself as the subject of her own gazeand by extension, that of the viewer-it is her subjectivity (or its imaginary equivalent) that leaks out of her here as if to assert that her own mastery over this image is illusory-a form of violence is still visited upon her. However, our own sense of mastery over the female form is trumped or undermined by Woodman who offers herself up knowingly as an object to be consumed primarily by her own gaze - as if to say defiantly, "go ahead then, try to objectify me if you can." Both her mastery over her own image and our visual pleasure are always already precluded.

Here, Woodman stages once again a scene of doubling: she is at once both the subject and object of her own gaze; again, Raymond notes that: "Woodman's self-portraits picture the heuristic project of trying to see: the [...] moment when you see yourself seeing" (2010, p. 82). If the photograph comes to be read as a moment of capture and stasis, Woodman stages an event in which her body is not only made imminent within its environment, but also is cast as liminal, unfixed and in-between. Caught between looking and being to-be-looked-at, this body gives nothing away in terms of its own history. For what we see is not biographical-much as many of the titles of her images seem to intimate personal motivation-but a subjectivity that comes into being as it is created, in a sense, via the photographic apparatus and its coterminous ideology and norms. As such, Woodman's work functions not as an auteurist statement, but investigates the always already ideologically laden ways in which a being becomes something rather than nothing for someone else. In I Could No Longer Play, I Could Not Play by Instinct, it is striking, for instance, that Woodman's head is severed from her body-indeed, for some- 
one who made so many self-portraits, her face is often (d)effaced or left out of the frame altogether ${ }^{5}$. Initially, this seems a statement about how objectification divests us or evacuates us of our essential humanity, but closer inspection also reveals a violence that subsists within this moment: the repetition of the artist's face and the disarming and gleaming presence of the knife foreground the power of that subjectivity which, at first, seems to be dispossessed yet is renewed via the image's very construction. Moreover, the nature of the long exposure technique gives time back to the image: this is an entity that endures and refuses capture.

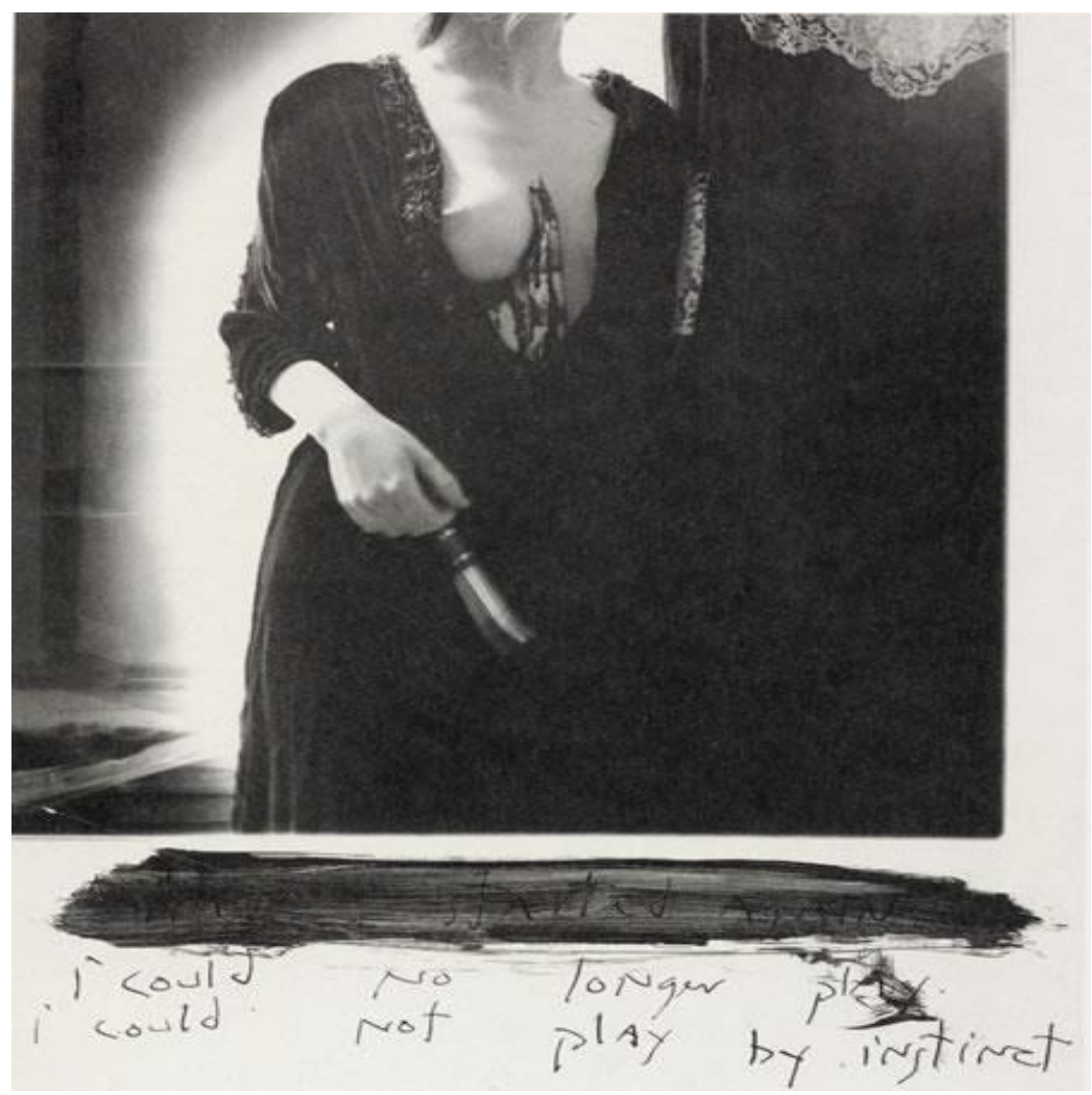

Figure 3: I Could No Longer Play, I could Not Play by Instinct. 1977.

\footnotetext{
${ }^{5}$ In fact, Elisabeth Bronfen notes that even when Woodman's face is clearly recognisable across a series of images, she never looks consistently the same. See Bronfen (2014, p. 18).
} 
In Woodman's work the surface of the image is anything but fixed and lifeless; rather, it is the surface upon which the crisis of subjectivity is played out. Her reintroduction of time (as that which throws into crisis the notion of abiding identity) into the image is a form of radical resistance against not only exhaustive readings of her work and her own identity as an artist, but also against the affective death the medium itself delivers upon her body. For what is revealed in Woodman's images is the impossibility of capture, of summation, of finality. By examining what it means to be rendered as an image for another, Woodman herself becomes altogether more complex and elusive. Her defiant presence as an artist, in all its vulnerability and ambiguity, endures in its fight against erasure. Rather than staging an act of disappearance, it seems to me, as I have argued here, that Woodman's work is marked by an elusive yet insistent manifestation that taunts both the viewer and the camera: here I am (not); you may try, but you cannot take my existence from me.

\section{References}

Barthes, R. (2000). Camera Lucida. London: Vintage Books.

Baudrillard, J. (1994). Simulacra and simulation. Michigan: University of Michigan Press. https://doi.org/10.3998/mpub.9904

Berger, J. (2008). Ways of seeing. London: Penguin Books.

Bronfen, E. \& Schor, G. (Eds.). (2014). Francesca Woodman: Works from the Sammlung Verbund. Germany: König.

Butler J. (2005). Giving an account of oneself. New York: Fordham University Press. https://doi.org/10.5422/fso/9780823225033.001.0001

Debord, G. (1992). Society of the spectacle. London: Rebel Press.

Elias, A. S. \& Gill, R. (2017). Beauty surveillance: The digital self-monitoring cultures of neoliberalism. European Journal of Cultural Studies, 21(1), 59-77. https://doi.org/10.1177/1367549417705604

McRobbie, A. (2015). Notes on the perfect: Competitive femininity in neoliberal times. Australian Feminist Studies, 30(83), 3-20. https://doi.org/10.1080/08164649.2015.1011485

Mirzoeff, N. (2015). How to see the world. London: Penguin.

Pedicini, I. (2012). Francesca Woodman. The Roman years: Between flesh and the film. Rome: Contrasto.

Phelan, P. (2002). Francesca Woodman's photography: Death and the image one more time. Signs, 27(4), 979-1004. https://doi.org/10.1086/339640

Raymond, C. (2010). Francesca Woodman and the Kantian sublime. London: Ashgate.

Riches, J. (2004). A disappearing act: Francesca Woodman's portrait of a reputation. Oxford Art Journal, 27(1), 95-113. https://doi.org/10.1093/oaj/27.1.95 
Sherlock, A. (2013). Multiple expeausures: Identity and alterity in the "Self-Portraits" of Francesca Woodman. Paragraph, 36(3), 376-391. https://doi.org/10.3366/para.2013.0100

Sontag, S. (1979). On photography. London: Penguin.

Steinhauer, J. (2012, May). Finding Francesca Woodman. The Paris Review. Retrieved November 28, 2016 from http://www.theparisreview.org/blog/2012/05/23/finding-francesca-woodman/.

Townsend, C. (2007). Francesca Woodman. London: Phaidon Press.

Wolf, N. (1991). The beauty myth. London: Vintage Books.

Anna Backman Rogers is Professor of Culture, Aesthetics and Feminist Theory at the University of Gothenburg, Sweden. Her latest book is Still Life: Notes on Barbara Loden's Wanda (Punctum, 2021). 